Marta C. G. Braga [UFSC], Vania R. Ulbricht [UFSC]

\title{
Acessibilidade em Ambientes Virtuais de Aprendizagem: Abordagem Teórica.
}

\author{
Accessibility in Virtual Learning Environment: Theoretical Approach.
}

acessibilidade, interação humano computador, design instrucional

\begin{abstract}
O artigo apresenta os requisitos da acessibilidade Web que podem orientar o designer instrucional quando da escolha de Ambientes Virtuais de Aprendizagem (AVAs) utilizados na interação de professores e alunos em cursos on-line e, por meio dos quais alunos entram em contato com conteúdos, atividades de aprendizagem e avaliações. O design instrucional exige múltiplos conhecimentos e se realiza na interação com várias áreas, tais como o design de interface, a arquitetura da informação e outras. O designer instrucional é aquele que faz a mediação entre as teorias pedagógicas e a tecnologia propondo estratégias para que os objetivos da aprendizagem se realizem. Ele deve centrar as estratégias na audiência praticando o design para todos. A partir da abordagem teórica, o presente trabalho pretende colaborar para minimizar as dificuldades de acesso em AVAs e auxiliar na inclusão digital de usuários com inabilidades.
\end{abstract}

acessibility, human-computer interaction, instructional design

The paper presents the requisites of the Web accessibility that can guide instructional designer when of the choice of Virtual Learning Environments (VLE's) used in the interaction of teachers and pupils in courses online and, through which pupils get in contact with contents, activities of learning and evaluations. The instructional design demands multiple knowledge and happens in the interaction with several areas, such as the interface design, the information architecture and others. The instructional designer is that one make the mediation between the pedagogical theories and the technology proposing strategies so that the objectives of the learning happen. He must center the strategies in the audience practicing the design for all. From the theoretical approach, the present work intends to collaborate to minimize the difficulties of access in VLE'S and assistant in the digital inclusion of users with inabilities.

\section{Introdução}

Acredita-se que a integração de pesquisas sobre Acessibilidade Web e Design Instrucional venham a ocorrer com maior freqüência a partir deste momento, visto que, um novo público com diversos tipos de inabilidades está buscando pelos cursos de Educação a Distância. A tônica da questão parece ser a busca por soluções que viabilizem o acesso desta nova população aos Ambientes Virtuais de Aprendizagem (AVAs) sem que se exponham as dificuldades destes usuários, como os portadores de deficiência visual, por exemplo. O Design Universal recomenda que os produtos não devam ser projetados especificamente para uma população, mas que sejam utilizados pela maior parcela possível de usuários, beneficiando pessoas de qualquer idade e habilidades (ORNELLA, STÉPHANIE, 2006). Neste sentido, este artigo vai se apoiar nas linhas guias da Web Accessibility Initiative (WAI) da Word Wide Web Consortium (W3C) com o objetivo de apresentar requisitos que podem auxiliar os designers instrucionais quando da escolha de AVAs. Em primeiro momento o trabalho apresenta o contexto da Interação Humano Computador (IHC), em seguida conceitua termos relacionados com a IHC e a Acessibilidade Web apontando algumas dificuldades de usuários na utilização da Web. Passa então, a expor os requisitos da acessibilidade Web que devem ser levados em consideração na escolha de AVAs e finalmente apresenta as considerações finais.

\section{Interação Humano Computador e Acessibilidade Web}

Quando as primeiras linhas de linguagem de programação começaram a ser escritas apenas os especialistas e técnicos lidavam com os computadores. No entanto, depois que os primeiros microcomputadores foram lançados no mercado e passaram a ser objeto de consumo de usuários comuns evidenciou-se a necessidade do desenvolvimento de meios que tornassem a 


\section{Infodesıgn}

máquina mais fácil de ser manipulada. A disciplina Interação Homem-Computador mais conhecida pela sigla $\mathrm{HCl}$ (Human-computer Interaction) foi criada com o objetivo de estudar a comunicação entre o homem e o computador (BUTLER et all, 1999). Nesta trajetória, o computador se tornou uma ferramenta indispensável para a realização de atividades nas mais diversas áreas de conhecimento. Desta forma, pesquisadores, engenheiros e designers de hardware e software trabalham para torná-lo uma ferramenta mais amigável e intuitiva ao homem buscando auxílio no campo da Psicologia Cognitiva e Comportamental, na Lingüística e na Ergonomia.

Desde que a primeira conferência sobre fatores humanos em sistemas computacionais foi apresentada em Gaithersburg, Maryland, em 1982, tornou-se próspera a publicação de milhares de documentos de pesquisa. O campo cresceu e lutou pela sua natureza multidisciplinar. As pesquisas tecnológicas foram direcionadas para os periféricos e reconhecimento de voz, pensavase em formas de interação como linguagens de comando, desenho de menus e manipulação direta. As pesquisas de $\mathrm{HCl}$ analisaram aplicações na Medicina, Educação, Finanças, uso doméstico e entretenimento. Adicionalmente, o impacto do desenvolvimento tecnológico tal como a disseminação da computação e a Internet, conduziram a uma maior atenção sobre os assuntos humanos como privacidade, confiança, e segurança. O papel do usuário de tecnologia mudou e evoluiu em pesquisa e desenvolvimento (P\&D) dentro da indústria de computador. O uso da tecnologia que se dava para atender a necessidade humana de completar alguma tarefa, agora tenta olhar para o usuário de forma mais complexa: como um humano em um sistema social no qual o computador tem um papel crescentemente e importante (KARAT \& KARAT, 2003).

Abascal, Arrue e Vigo (2007) constatam a importância da internet para a comunicação e o vertiginoso crescimento das diversas atividades na Web, tais como: negócios, lazer, aprendizagem dentre outras. Contudo, afirmam que a inúmera quantidade de ambientes existentes hoje é inacessível em graus variados ocasionando a dificuldade de acesso na Web por pessoas com inabilidades.

O ciclo de vida de um ambiente Web é muito curto e os designers estão sempre lançando novas versões em pequenos períodos de tempo provocando prejuízo na qualidade e acessibilidade do produto final. Outra questão apontada por Abascal, Arrue e Vigo (2007) é a falta da avaliação da acessibilidade durante o processo de desenvolvimento do ambiente, o que vem ocorrendo apenas nas últimas fases do processo e por instrumentos automáticos. Desta forma, a constatação de erros obriga ao re-desenho completo do sistema. Os autores identificam a falta de metodologias de desenvolvimento que incorporem a acessibilidade como uma prioridade e afirmam que, a existência de uma metodologia pode trazer conscientização da necessidade da acessibilidade aos profissionais e organizações e melhorar a qualidade dos produtos, bem como, podem facilitar a sua manutenção

$\mathrm{Na}$ tentativa de superar as questões relativas à acessibilidade foram tomadas algumas iniciativas, tais como o estabelecimento de leis contra a exclusão digital. Entretanto, a questão torna-se complexa na medida em que os designers de ambientes Web desconhecem as necessidades das pessoas com inabilidades. Eles precisam seguir critérios muito específicos como linhas guias para realizarem seu trabalho. Nesta perspectiva, a Web Accessibility Initiative (WAI) da Word Wide Web Consortium (W3C) tem desenvolvido especificações, guias, software e ferramentas para a realização do paradigma do "design para todos" (ABASCAL, ARRUE, VIGO, 2007).

Outro aspecto que merece atenção é a organização da informação na Web. Nielsen (1990) já alertava para o problema da desorientação de usuários em espaços de informação. É crescente a quantidade de conteúdo na Internet, junto aumenta a dificuldades para os usuários compreenderem a ligação entre os documentos. Muitas vezes é necessário navegar pelas páginas para saber seu conteúdo (PIMENTEL, 2002; DIAS, 1997), pois a navegação entre as páginas é realizada, na maioria das vezes, por palavras chaves que muitas vezes são inexatas em relação ao contexto da página a qual está conectada (HARPER, 2004). Também, a falta de uma estrutura e da sistematização da informação é uma das causas da dificuldade de usuários encontrarem o que procuram (CASTELEY, 2003).

Edwards e Hardman (1989, apud DIAS, 1997) apontam três sensações pelas quais passam os usuários quando se encontram perdidos: (a) não sabem aonde ir, (b) sabem aonde ir, mas não sabem como voltar, (c) ou não sabem onde estão em relação à estrutura total da hipermídia. Foss (1989, apud DIAS, 1997) descreve algumas conseqüências indesejáveis de navegação observadas em usuários de sistemas de hipermídias: o desvio de rumo que ocorre quando os usuários perseguem múltiplos caminhos e digressões que podem levá-los a perder a sua localização, esquecer o caminho de volta ou negligenciar caminhos importantes relacionados à tarefa principal por causa da sua distração constante. Estas dificuldades são comuns aos usuários e vêm sendo uma grande preocupação por parte dos projetistas da arquitetura da informação.

Para Rosenfeld (2002) as pessoas tendem a manter um procedimento antigo e já 
dominado para solucionar problemas envolvendo novos objetos de estudo. Aos poucos, com a finalidade de melhorar os resultados, novas experiências permitem a adoção de novos métodos. Este é o caso da Organização da Informação que até bem pouco tempo era tarefa exclusiva de bibliotecários. Com o surgimento da Internet e da descentralização da informação, todas as pessoas que produzem conteúdos para publicação na Internet deparam-se com a tarefa da classificação. O mais usual é que elas apliquem o que já conhecem e adotem uma linguagem que simule aquela usada por bibliotecários (ROSENFELD, 2002). Este oceano de informações está organizado de várias formas e percorrido sob múltiplas representações mentais de navegação.

Estas são questões que permeiam o desenvolvimento dos ambientes hipermidiáticos e, portanto, precisam ser levadas em consideração na escolha de um Ambiente Virtual de Aprendizagem (AVA), pois a Internet, como meio de interação entre professores e alunos, requer a utilização de aplicativos que permitam a ocorrência efetiva da aprendizagem, bem como, a tendência do ensino a distância que, em outros tempos, se utilizou exclusivamente do meio impresso, agora se apropria das diversas mídias para disponibilizar conteúdos. O Blended Learning permite diversificar as estratégias de aprendizagem e em conseqüência desta combinação de canais, o Brasil vem apresentando forte crescimento na educação on-line. O Elearning encontra-se em segundo lugar de utilização perdendo espaço apenas para a mídia impressa (ANUÁRIO BRASILEIRO ESTATíSTICO DE EDUCAÇÃO ABERTA E A DISTÂNCIA, 2006). A educação on-line passou a atrair diversos tipos de audiência aumentando a participação ativa de novos públicos, principalmente dos novatos na utilização da Internet e daqueles com inabilidades.

\section{Ambientes Virtuais de Aprendizagem (AVAs) e Acessibilidade}

Os Ambientes Virtuais de Aprendizagem (AVAs), concebidos como metáforas da escola convencional, são um apoio consistente à Educação a Distância (EaD), bem como, estão modificando as práticas de ensinar/aprender e propiciando uma educação mais significativa e motivadora para os alunos. Estes ambientes são sistemas gerenciadores da aprendizagem on-line e oferecem apoio aos serviços para estudantes, professores e administradores, tais como: controle de acesso, distribuição de conteúdos, ferramentas de comunicação, pesquisas, questionários de avaliação e organização de usuários por grupos (PAUSEN, 2002). Através destes ambientes ocorrem as interações entre professores e alunos, alunos e alunos, alunos e conteúdos, professores e professores e professores e conteúdos (ANDERSON, 2004).

Além de fazer parte de uma das etapas do projeto instrucional de um curso a escolha de um AVA obedece a critérios determinados pelo designer instrucional para o atingimento dos objetivos da educação. Dentre outras coisas, AVAs são constituídos por uma arquitetura interna e uma interface por meio da qual os usuários estabelecem contato com todo o ambiente, navegando pelos diversos links e interagindo quando necessário (BRAGA, 2007).

Diante da diversidade das novas mídias utilizadas na Educação a Distância, as pesquisas sobre o design instrucional tornam-se freqüentes e são importantes para o domínio dos métodos de gestão do E-learning e de apoio as pesquisas e proposições de modelos para a educação online. Para Filatro:

'O Design Instrucional é compreendido como a ação institucional e sistemática de ensino, que envolve o planejamento, o desenvolvimento e a utilização de métodos, técnicas, atividades, materiais, eventos e produtos educacionais em situações didáticas específicas, a fim de facilitar a aprendizagem humana a partir dos princípios de aprendizagem e instrução conhecidos (FILATRO, 2004, p:64).'

O design instrucional pode ser abordado a partir da visão sistêmica ${ }^{1}$ o que facilita o processo de idealização e produção de conteúdos através de interações constantes entre os elementos (etapas do processo), bem como, as avaliações durante o processo realimentam o sistema podendo otimizar a realização das operações. Para abordar o design instrucional a partir de uma perspectiva sistêmica é preciso entendê-lo como:

'Um enfoque global e interdisciplinar que envolve a resolução de problemas de maneira disciplinada, mantendo prioridades em mente. Cada subsistema, que faz parte do sistema global, pode ser elaborado, adequado, verificado e operado para alcançar o objetivo global, eficientemente (Rowntree, 1974, apud ROMISZOWSKI, 2007).'

Nesta perspectiva, o designer instrucional necessita compreender o todo e, principalmente, a dinâmica de interações entre as etapas do processo de design instrucional. Dentre as etapas pertinentes ao processo está a escolha das mídias a serem utilizadas e, assim, há que se pensar na implantação de um AVA acessível, de fácil utilização pelos usuários e na forma de organizar as informações para que eles encontrem os conteúdos e realizem as

1 Em referência a Teoria Geral de Sistemas (BERTALANFFY, 1972). 


\section{Infodesıgn}

atividades de aprendizagem efetivamente.

De acordo com a Web Accessibility Initiative (WAI),

'A acessibilidade $W e b$ significa que as pessoas com inabilidades podem usar a Web. Mais especificamente, a acessibilidade Web significa que as pessoas com inabilidades podem perceber, entender, navegar, e interagir com a $W e b$, e que podem contribuir para a Web. Acessibilidade Web abrange também outros beneficiados, incluindo pessoas idosas com mudanças nas capacidades devido ao envelhecimento (W3C, 2007).'

O conceito de acessibilidade está relacionado ao de usabilidade e juntos podem determinar a satisfação do usuário, a eficácia e a eficiência. A acessibilidade pode ser entendida como parte da usabilidade (Thatcher et al., 2002 apud ABASCAL, ARRUE, VIGO, 2007), visto que, a usabilidade é 'A capacidade que um sistema interativo oferece a seu usuário, em um determinado contexto de operação, para a realização de tarefas, de maneira eficaz, eficiente e agradável' (ISO 9241, 2007). De acordo com Nielsen (1993) a usabilidade não é simplesmente uma propriedade da interface do usuário, mas ela tem múltiplos componentes e está associada a cinco questões: fácil entendimento, eficiência, fácil recordação, baixo índice de erros e ser agradável.

A interface é a esfera de atuação da interatividade estrutural entre instrumento e usuário (BONSIEP, 1997). [...] uma superfície de contato, de tradução, de articulação entre dois espaços, duas espécies, duas ordens de realidade diferentes: de um código para outro, do analógico para o digital, do mecânico para o humano... Tudo aquilo que é tradução, transformação passagem, é da ordem da interface (LEVY, 1993, p:181).

As interfaces gráficas, da interação humano-computador, são constituídas por ferramentas metafóricas tais como janelas, ícones, menus e teclas. Metáfora da realidade com a qual o usuário já está familiarizado e os elementos sobre o monitor abrem espaço para a ação de comandos e processamentos cujos resultados serão exibidos em um dispositivo de saída como um monitor ou impressora. Assim, interatividade, dentro do campo da comunicação e tecnologia, é o expediente que permite a transferência ou 'comunicação de conhecimento, de idéia, de expressão artística, de sentimento' (GOSCIOLA, 2003, p: 87) e 'O design de interface é essencialmente o design da navegação e da apresentação da informação. (...) uma questão de equilibrar a estrutura e as conexões de menu, conteúdos e outras conexões para documentos e gráficos com o objetivo de criar uma hierarquia de menus e páginas de forma natural, bem estruturado e de uso fácil' Galitz (2002, [s.p.], tradução nossa).

O design de interface está relacionado a usabilidade e a arquitetura da informação. A Web é um ambiente flexível para trabalhar a organização. Ela está livre das limitações físicas e pode receber múltiplos sistemas de navegação sobre um mesmo conteúdo. (ROSENFELD, 2002). Apesar desta flexibilidade e exatamente por causa dela a tarefa de organizar informações é complexa. A não-linearidade do hipertexto define um espaço com vários caminhos. Assim, a navegação pelos links torna-se uma espécie de experimentação do domínio e o modelo do comportamento do usuário representa, entre outras coisas, a sua compreensão da organização dos conteúdos. A desorganização da informação pode causar uma interface confusa. Desta forma, estudos demonstram que com o aumento da desorientação a aprendizagem em AVAs provavelmente não se realizará da forma esperada (Beasley, 1994; Tripp e Roby, 1990 apud GRIFFIN, 2000).

\section{Requisitos da Acessibilidade Web para a escolha de AVAs}

Web Content Accessibility Guidelines (WCAG) criada pela WAI estão sendo usadas para a avaliação da acessibilidade em Web sites e, portanto, também podem ser utilizadas na escolha de AVAs. Elas listam pontos a serem checados e cada ponto tem um nível de prioridade de acordo com o impacto causado sobre a acessibilidade. São três técnicas de testes específicos a serem verificados e conformados em prioridades:

- Conformação de nível 1 (A): Todas as prioridades do nível 1 devem estar satisfeitos completamente.

- Conformação de nível 2 (AA): Todas as prioridades dos níveis 1 e 2 devem estar satisfeitos completamente.

- Conformação de nível 3 (AAA): Todas as prioridades dos níveis 1, 2 e 3 devem estar satisfeitos completamente (ABASCAL, ARRUE, VIGO, 2007, p:187, tradução nossa). 
Segundo as linhas guias da última versão $\mathrm{WCAG}^{2}$, a de número 2.0 e datada de 17 de maio de 2007, um ambiente Web, incluindo-se os AVAs, deve ser:

- Perceptível: faça o conteúdo perceptível por qualquer usuário.

- Compreensível: faça o conteúdo e controle compreensível a tantos usuários enquanto possivel.

- Robusto: use tecnologias de Web que maximizem a possibilidade do conteúdo se adaptar a tecnologias de acessibilidade atuais e futuras e a agentes de usuário.

- Operável: assegure que os elementos de interface no conteúdo sejam operáveis por qualquer usuário (ABASCAL, ARRUE, VIGO, 2007, p:187, tradução nossa).

Aplicações para Web devem considerar as questões relativas à padronização. A International Organization for Standardization (ISO) 9126 padrão (ISO, 2001) determina seis pontos para a qualidade de softwares: funcionalidade, confiança, eficiência, usabilidade, manutenibilidade e portabilidade (ABASCAL, ARRUE, VIGO, 2007).

'Deste ponto de vista, a qualidade é uma composição de propriedade do produto, envolvendo um conjunto de atributos interdependentes (Brajnik, 2001). Essas características podem ser tomadas como os atributos que qualquer produto de software tem de cumprir. A ISO 9126 também define um modelo de qualidade de produto de software que inclui tanto qualidade interna como a qualidade no uso. Para objetivos de avaliação, este padrão deve ser usado em conjunto com o ISO/IEC 14598-1 (ISO, 1999) que fornece métodos da medição e avaliação da qualidade de software. Os modelos específicos da avaliação de qualidade de Web site também foram propostos (ver Mich, Franch, e Gaio, 2003). (ABASCAL, ARRUE, VIGO, 2007, p:187, tradução nossa).'

\section{Considerações finais}

Esta pesquisa teve como objetivo apresentar os requisitos da acessibilidade Web no sentido de orientar o designer instrucional na fase da escolha de mídias, especificamente os AVAs. O design instrucional abrange uma pluralidade de áreas para se realizar, desta forma, procurou-se contextualizar a IHC, conceituar termos das áreas relacionadas com o tema do trabalho, foram apresentadas algumas dificuldades de usuários na navegação na Web e os requisitos da acessibilidade Web que podem auxiliar na escolha de AVAs.

Conclui-se ao final desta pesquisa que o designer instrucional em sua práxis deverá incorporar estudos relativos a acessibilidade em AVAs, pois uma nova audiência de pessoas com inabilidades começa a participar de cursos a distância e faz-se necessário atentar para que não se exponham suas deficiências, mas que recebam conteúdo e pratiquem atividades em igualdade com todos os alunos, participem do mesmo ambiente virtual e possam contribuir colaborativamente exercitando a aprendizagem autônoma.

Destaca-se que as padronizações e linhas guias estabelecidas pelos diversos instrumentos que estão sistematizando as questões relativas a acessibilidade Web e a usabilidade, bem como as pesquisas sobre a organização da informação em interfaces devem ser a base de orientação para os designers instrucionais encaminharem os processos do DI na busca do Design Universal.

\section{Referências}

Abascal, J.; Arrue, M; Vigo, M. (2007). A Methodology for Web Accessibility Development and Maintenance. In.: Human Computer Interaction research in Web design and Evaluation. Zaphiris, P; Kurniawan, Sri.. London: Idea Group.

Anderson, T. (2004). Toward a Theory of Online Learning. In: Anderson, T.; Elloumi, F. (Ed.). Theory and Practice of Online Learning. Athabasca: Athabasca University. Cap. 2, p. 1421. Disponível em: <http://cde.athabascau.ca/online_book/>. Acesso em: 1 jul. 2005.

Anuário Brasileiro Estatístico de Educação Aberta e a Distância. (2005) 1a. ed.. São Paulo: Instituto Monitor, v. 2. Disponível em: <http://www.abraead.com.br/anuario.swfs. Acesso em: 01 ago. 2006.

Braga, M. C. G. (2007). Estratégia on-line para capacitação de professores em aprendizagem por meio das HQs: abordagem centrada na educação através do design (EdaDe). 217 f. Dissertação (Mestrado) - Curso de Engenharia e Gestão do Conhecimento, 


\section{Infodesıg}

Departamento de Engenharia e Gestão do Conhecimento, Universidade Federal de Santa Catarina, Florianópolis.

Bertalanffy, L. Von (1972). The History and Status of General Systems Theory. In: General Systems Theory. The Academy Of Management Journal, 4. ed. Cap. 15, p. 407-424. Disponível em: <http://www.jstor.org/>. Acesso em: 15 jul. 2007.

Bonsiepe, G. (1997). Design: do material ao digital. Florianópolis: FIESC/IEL.

Butler, K. A. ; Jacob, R. J. K. ; John, B. E. (1999) . Human-Computer Interaction: Introduction and Overview. ACM Press: New York. Disponível em: http://portal.acm.org. Acesso em: 25 de março de 2005.

Filatro, Andréa (2004). Design Instrucional Contextualizado: educação e tecnologia. São Paulo: Editora Senac São Paulo.

Gosciola, V. (2003). Roteiro para as novas mídias: do game à tv interativa. São Paulo: Ed. Senac.

International Organization for Standardization. ISO 9241: Disponível em <http://WWW.iso.org/iso/en> Acesso em: 5 de dez 2007.

Karat, J. \& Karat, Clare-Marie (2003). The evolution of user-centered focus in the humancomputer interaction field. IBM Systems Journal, vol 42, n. 4.

Lee, W. W., Owens, D. L. (2004). Multimedia-Based Instructional Design. San Francisco: John Wiley \& Sons, Inc..

Lévy, P. (1993). As tecnologias da inteligência: o futuro do pensamento na era da informática. Rio de Janeiro: Editora 34 Ltda.

Nielsen, J. (1990). The Art of navegation. New York: ACM Press. (1993). Usability Engineering. San Diego: Morgan Kaufmann.

Ornella, P.; Stéphanie, B. (2006). Universal Design for Mobile Phones: A Case Study. CHI 2006 - Work-in-Progress, Montréal. Disponível em: http://www.acm.org. Acesso em: 23 jul 2007.

Pausen, M. F. (2002). Online Education Systems: Definition of Terms. Webeducation Systems: ZIFF Papiere, Hagen, n. 118, p.23-28. Disponível em: <http://www.fernunihagen.de/ZIFF/ZP_118.pdf>. Acesso em: 10 nov. 2006.

Romiszowski, A. J. (2007). Design e Desenvolvimento Instrucional: Um modelo sistêmico em quatro níveis. Associação Brasileira de Educação A Distância. Disponível em: <http://www.abed.org.br>. Acesso em: 19 jul. 2007.

\section{Sobre as autoras}

Marta C. G. Braga, Doutoranda e mestra em Engenharia e Gestão do Conhecimento pela Universidade Federal de Santa Catarina e Bacharel em Composição de Interiores pela Universidade Federal do Rio de Janeiro.

marta@goul.pro.br

Vânia R. Ulbricht, Licenciada em Matemática, Mestre e Doutora em Eng. de Produção, pela UFSC. Professora do Mestrado Acadêmico em Design da Universidade Anhembi Morumbi. Pesquisadora dos Grupos de Pesquisa: Design, Criação e Novas Mídias e Ambientes Hipermídia para Aprendizagem. Professora Voluntária nos programas de Pós-Graduação em Arquitetura e Engenharia e Gestão do Conhecimento junto a UFSC.

ulbricht@floripa.com.br 